OPEN ACCESS

Edited by:

Prabakaran Ponraj,

Intrexon, United States

Reviewed by:

Robyn Stanfield,

The Scripps Research Institute,

United States

Stanley Nithianantham,

University of California, Davis,

United States

*Correspondence:

Roy A. Mariuzza

rmariuzz@umd.edu

Specialty section:

This article was submitted to B Cell Biology,

a section of the journal

Frontiers in Immunology

Received: 16 November 2017

Accepted: 15 January 2018

Published: 01 February 2018

Citation:

Mishra AK and Mariuzza RA (2018) Insights into the Structural Basis of Antibody Affinity Maturation from Next-Generation Sequencing.

Front. Immunol. 9:117. doi: 10.3389/fimmu.2018.00117

\section{Insights into the Structural Basis of Antibody Affinity Maturation from Next-Generation Sequencing}

\author{
Arjun K. Mishra ${ }^{1,2}$ and Roy A. Mariuzza ${ }^{1,2 *}$ \\ ${ }^{1}$ W. M. Keck Laboratory for Structural Biology, Institute for Bioscience and Biotechnology Research, University of Maryland, \\ Rockville, Rockville, MD, United States, '² Department of Cell Biology and Molecular Genetics, University of Maryland, \\ College Park, College Park, MD, United States
}

Affinity maturation is the process whereby the immune system generates antibodies of higher affinities during a response to antigen. It is unique in being the only evolutionary mechanism known to operate on a molecule in an organism's own body. Deciphering the structural mechanisms through which somatic mutations in antibody genes increase affinity is critical to understanding the evolution of immune repertoires. Next-generation sequencing (NGS) has allowed the reconstruction of antibody clonal lineages in response to viral pathogens, such as HIV-1, which was not possible in earlier studies of affinity maturation. Crystal structures of antibodies from these lineages bound to their target antigens have revealed, at the atomic level, how antibodies evolve to penetrate the glycan shield of envelope glycoproteins, and how viruses in turn evolve to escape neutralization. Collectively, structural studies of affinity maturation have shown that increased antibody affinity can arise from any one or any combination of multiple diverse mechanisms, including improved shape complementarity at the interface with antigen, increased buried surface area upon complex formation, additional interfacial polar or hydrophobic interactions, and preorganization or rigidification of the antigenbinding site.

\footnotetext{
Keywords: antibody, affinity maturation, somatic hypermutation, HIV-1, structural biology, next-generation sequencing
}

\section{INTRODUCTION}

The ability of the humoral immune system to generate high-affinity binders for virtually any antigen is predicated on its capacity to produce large repertoires of antibodies encompassing a vast array of specificities and to then select members of this repertoire with high affinity for a particular immunogen (1-3). The extensive sequence diversity of antibody molecules derives from several sources: (i) combinatorial diversification, whereby two sets of light (L) chain gene segments, $\mathrm{V}_{\mathrm{L}}$ and $\mathrm{J}_{\mathrm{L}}$, and three sets of heavy $(\mathrm{H})$ chain gene segments, $\mathrm{V}_{\mathrm{H}}, \mathrm{D}$, and $\mathrm{J}_{\mathrm{H}}$, rearrange to produce functional variable (V) regions; (ii) imprecise joining of these gene segments; and (iii) somatic hypermutation, by which point mutations, as well as insertions and deletions (indels), are introduced throughout the sequences encoding $\mathrm{L}$ and $\mathrm{H}$ chains (4). B cells expressing antibodies with improved affinity are better equipped to compete for antigen and thus receive signals that result in preferential expansion and further antibody sequence diversification via additional rounds of somatic hypermutation (1-3). Through this rapid evolutionary process of mutation and selection, antibody affinity typically improves 10 - to 5,000-fold during the course of an immune response, bolstering host defense.

Recent advances in next-generation sequencing (NGS) have revolutionized the analysis of antibody repertoires by dramatically increasing sample depth compared to previous low-throughput 
methods (5). In addition, new methods have been developed for single-cell sequencing, which allow large-scale determination of paired $\mathrm{L}$ and $\mathrm{H}$ chains. These advances, in conjunction with computational tools for reconstituting antibody clonal lineages, can provide a genetic record for the evolutionary processes of recombination and somatic hypermutation in immune responses to specific microbial pathogens. Crystal structures of affinitymatured and germ line antibodies from such lineages in complex with their target antigens have produced new insights into the molecular basis of affinity maturation.

Here, we first review our understanding of the basic biophysical principles underlying affinity maturation before the arrival of NGS. We then summarize what studies of bulk B cell populations by NGS have taught us about the general features of antibody repertoire selection. Finally, we discuss structural studies of reconstructed antibody clonal lineages with special emphasis on the immune response to HIV-1, which has so far benefited most from the application of NGS and single-cell analysis to better understanding affinity maturation (6) (Table 1).

\section{STUDIES OF AFFINITY MATURATION PRIOR TO NGS}

Before the advent of NGS, a number of structural studies were carried out comparing affinity-matured antibodies and their putative germ line precursors bound to the same antigen. In studies involving small molecules (haptens) such as phenyloxazolone

TABLE 1 | Structural studies of antibody clonal lineages reconstructed using next-generation sequencing.

\begin{tabular}{|c|c|c|c|}
\hline $\begin{array}{l}\text { Antibody } \\
\text { lineage }\end{array}$ & Specificity & PDB code & Reference \\
\hline \multirow[t]{2}{*}{$\mathrm{CH} 58$} & $\begin{array}{l}\text { HIV-1 envelope } \\
\text { glycoprotein (Env) } \\
\text { gp120 }\end{array}$ & $4 \mathrm{HPO}$ & (7) \\
\hline & & 4RIS, 4RIR & (8) \\
\hline \multirow[t]{3}{*}{ VRC01 } & HIV-1 Env gp120 & $\begin{array}{l}\text { 4JPV, 4JPW, 4LSP, 4LSQ, } \\
\text { 4LSR, 4LSS, 4LST, 4LSU, } \\
\text { 4LSV }\end{array}$ & (9) \\
\hline & & 5F7E, 5FA2, 5FEC, 5IGX, 5190 & (10) \\
\hline & & 4JPK, 4JPI & (11) \\
\hline VRC03 & HIV-1 Env gp120 & 5JOF, 5JXA & $(12)$ \\
\hline \multirow[t]{2}{*}{$\mathrm{CH} 103$} & HIV-1 Env gp120 & 4JAM, 4JAN & $(13)$ \\
\hline & & 4QHK, 4QHL, 4QHM, 4QHN & $(14)$ \\
\hline \multirow[t]{3}{*}{ PGT121 } & HIV-1 Env gp120 & $4 \mathrm{NCO}$ & $(15)$ \\
\hline & & 4R26, 4R2G & $(16)$ \\
\hline & & 5CEX, 5CEY, 5CEZ & $(17)$ \\
\hline PCT64 & HIV-1 Env gp120 & $5 F E H$ & $(18)$ \\
\hline CAP256 & HIV-1 Env gp120 & $\begin{array}{l}\text { 4OCR, 4OCS, 4OCW, 4OD1, } \\
\text { 4OD3, 4ODH, 4ORG }\end{array}$ & (19) \\
\hline ANC195 & HIV-1 Env gp120 & $5 \mathrm{CJX}$ & (20) \\
\hline C65 & Influenza A virus HA & $4 \mathrm{HKO}, 4 \mathrm{HK} 3,4 \mathrm{HKB}, 4 \mathrm{HKX}$ & $(21)$ \\
\hline $\begin{array}{l}\text { HV6- } \\
1+\text { HD3-3 }\end{array}$ & Influenza A virus HA & $\begin{array}{l}5 \mathrm{~K} 9 \mathrm{~J}, 5 \mathrm{~K} 9 \mathrm{~K}, 5 \mathrm{~K} 90,5 \mathrm{~K} 9 \mathrm{Q}, \\
5 \mathrm{KAN}, 5 \mathrm{KAQ}\end{array}$ & $(22)$ \\
\hline
\end{tabular}

and nitrophenyl phosphonate, rather than proteins, it was found that somatic mutations in complementarity-determining region (CDR) residues directly or indirectly implicated in binding hapten permit the formation of additional hydrogen bonds, electrostatic interactions, and van der Waals contacts (23-26). A particularly revealing case involved the matured $48 \mathrm{G} 7$ antibody, which binds nitrophenyl phosphonate $\sim 3,000$-fold more tightly than its germ line counterpart 48G7g (26). Large changes in the conformation of the antigen-binding site (paratope) of $48 \mathrm{G} 7 \mathrm{~g}$ were observed upon hapten engagement by this germ line antibody, whereas the free and hapten-bound forms of affinity-matured 48G7 showed few structural differences. Thus, affinity maturation in this case appeared to be driven largely by a mechanism of preorganizing the paratope into a conformation favorable for binding its hapten ligand (26). Such conformational preorganization was accompanied by a decrease in the flexibility of the paratope during the maturation process, which may increase specificity for the target antigen while reducing the possibility of cross-reactivity with other antigens, including self-antigens (27-29). The antibody maturation process appears to simultaneously select for both higher binding affinity and increased thermodynamic stability. In a study of matured antibody 93F3, which recognizes a small hapten, somatic mutations in the paratope that increased affinity were found to reduce the melting temperature of $93 \mathrm{~F} 3$ compared to its germ line precursor. However, the destabilizing effects of these mutations were compensated by additional somatic mutations in the $\mathrm{V}_{\mathrm{L}} / \mathrm{V}_{\mathrm{H}}$ interface, distal to the paratope (29).

The first structural study of the maturation of an antibody response to a protein antigen, instead of a hapten, involved a set of closely related antibodies specific for hen egg white lysozyme (HEL) (30). These antibodies represented different stages of affinity maturation, whereby the number of somatic mutations correlated with increasing affinity. Surprisingly, improved affinity could not be attributed to the formation of additional hydrogen bonds or salt bridges or to an increase in total buried surface area. Instead, affinity maturation resulted mainly from burial of increasing amounts of hydrophobic surface at the expense of polar surface, accompanied by improved shape complementarity at the $\mathrm{V}_{\mathrm{H}}-\mathrm{HEL}$ interface. The increase in hydrophobic interactions resulted from highly correlated structural rearrangements in antibody residues at the periphery of the interface with antigen, adjacent to the central energetic hot spot (30). Indeed, the periphery may offer more suitable sites for optimization because these regions are typically more flexible and tolerant to mutations than central sites (12), in agreement with the finding that somatic hypermutation spreads structural diversity generated by $\mathrm{V}(\mathrm{D}) \mathrm{J}$ recombination from central to peripheral regions of the antibody binding site (31).

Collectively, these structural studies showed that increased antibody affinity for small haptens or model protein antigens such as HEL can arise from any one or any combination of several variables, including additional interfacial hydrogen bonds or van der Waals contacts, conformational preorganization of the paratope, improved shape complementarity at the interface with antigen, or increased burial of total or hydrophobic surface area. These same basic strategies, as well as others, govern affinity maturation of antibody responses to biological antigens such as the envelope 
glycoproteins of HIV-1 and other viral pathogens, as discussed below. We first summarize what NGS of bulk B cell populations has taught us about antibody repertoire selection. We then discuss recent insights into affinity maturation gained from structural studies of antibody clonal lineages that were reconstructed using NGS (Table 1).

\section{NGS ANALYSIS OF ANTIBODY REPERTOIRES IN BULK B CELL POPULATIONS}

Next-generation sequencing of paired antibody L and $\mathrm{H}$ chains combined with computational modeling of antibody structures has been used to profile human antibody repertoire selection and maturation at the population level (5). In the most exhaustive study to date, a comparison of $\sim 55,000 \mathrm{~V}_{\mathrm{L}} / \mathrm{V}_{\mathrm{H}}$ pairs from naïve $\mathrm{B}$ cells with $\sim 120,000 \mathrm{~V}_{\mathrm{L}} / \mathrm{V}_{\mathrm{H}}$ pairs from antigen-experienced $\mathrm{B}$ cells, all isolated from human peripheral blood, showed that $\mathrm{V}_{\mathrm{L}}$ and $\mathrm{V}_{\mathrm{H}}$ genes pair in a purely combinatorial fashion with no detectable biases, but that certain $\mathrm{V}_{\mathrm{L}} / \mathrm{V}_{\mathrm{H}}$ gene pairs are significantly depleted or enriched in the antigen-experienced repertoire compared to the naive repertoire (32). Repertoire-wide computational structure prediction was carried out to characterize the physiochemical properties of the antibody paratopes. Whereas no appreciable differences in paratope hydrophobicity or solvent-accessible surface area were evident in antigen-experienced versus naïve antibodies, antigen-experienced $\mathrm{V}_{\mathrm{L}} \mathrm{CDR} 3$ and $\mathrm{V}_{\mathrm{H}} \mathrm{CDR} 3$ amino acid sequences displayed slightly increased positive charge compared to naïve sequences (32). Overall, however, the evolutionary processes of somatic hypermutation and affinity selection that occur in periphery blood did not leave a distinctive physiochemical imprint on the antigen-experienced antibody repertoire, even at the level of CDR3s, which are a major focus for somatic hypermutation. By contrast, bone marrow B cells expressing antibodies with positively charged CDR3 loops undergo preferential elimination at discrete developmental checkpoints before entering the periphery, possibly as a mechanism for reducing the risk of self-reactivity (33).

In a study to determine whether NGS could be used to detect antigen-specific sequences in bulk B cell populations, an analysis of identical CDR3 sequences that were shared by individuals previously vaccinated against Haemophilus influenzae type b identified a number of sequences known to be specific for this bacterium (34). Conserved CDR3 sequences were also observed in patients recovering from acute dengue infection (35), indicating convergent antibody evolution in different individuals exposed to the same antigens. In another study, NGS and single-cell sorting of peripheral blood plasmablasts were used to profile the acute antibody response to influenza A vaccination (36). Antibodies able to neutralize the virus were selected bioinformatically from clonal families. These vaccine-induced antibodies contained on average $>30$ somatic mutations overall. Notably, some antibodies exhibited higher affinities for hemagglutinins (HAs) from prior years' influenza strains than for the HA of the immunizing strain, suggesting recall of memory B cells expressing antibodies that had previously undergone affinity maturation (36).

\section{STUDIES OF AFFINITY MATURATION AFTER NGS}

Next-generation sequencing coupled with bioinformatics analysis has allowed, for the first time, the reconstruction of antibody clonal lineages and inference of germ line progenitor sequences, neither of which was possible in earlier studies of affinity maturation (37). However, an important caveat is that germ line sequences are predicted sequences that may differ from the true unmutated ancestor sequences. Whereas mutations in $\mathrm{V}_{\mathrm{L}}$ and $\mathrm{V}_{\mathrm{H}}$ gene segments can be identified with high confidence, the original $V_{\mathrm{L}} \mathrm{J}_{\mathrm{L}}$ and (especially) $\mathrm{V}_{\mathrm{H}} \mathrm{DJ} \mathrm{J}_{\mathrm{H}}$ junctional sequences of germ line antibodies are uncertain. In particular, it is impossible to know if insertions or deletions in these sequences took place during $\mathrm{V}(\mathrm{D})$ $J$ recombination or were introduced during $B$ cell affinity maturation. As a consequence, statistical methods must be used to infer the most likely unmutated common ancestor for an aligned set of sequences that are taken to be clonally related (37).

As measured by surface plasmon resonance (SPR), a putative germ line precursor of the anti-HIV-1 antibody $2 \mathrm{~F} 5$, which recognizes the gp41 subunit of the HIV-1 envelope glycoprotein (Env), bound recombinant gp41 with 500-fold lower affinity than the matured antibody $\left(K_{\mathrm{D}}=0.7 \mu \mathrm{M}\right.$ versus $\left.1.2 \mathrm{nM}\right)(38)$. Micromolar $K_{\mathrm{D}}$ sere also reported for germ line precursors of broadly neutralizing antibodies (bNAbs) $\mathrm{CHO}$ and $\mathrm{CH} 04$, which recognize the V2/V3 quaternary epitope of the gp120 subunit of HIV-1 Env (39). Although seemingly low, such affinities are nevertheless sufficient to trigger affinity maturation of unmutated B cells in vivo $(40,41)$.

By contrast, the putative germ line ancestors of several bNAbs specific for the CD4 binding site of HIV-1 Env (b12, NIH45-46, and 3BNC60) failed to show detectable binding to recombinant Envs, raising the question of how $\mathrm{B}$ cell maturation leading to the eventual production of these bNAbs was initiated $(42,43)$. Moreover, this failure was observed even though the amino acid sequences of the $\mathrm{V}(\mathrm{D}) \mathrm{J}$ junctions of the affinity-matured antibodies were left unchanged in the reconstructed germ line versions. One possibility is that maturation of anti-CD4 binding site bNAb precursors was triggered by non-HIV antigens and that the resultant antibody intermediates serendipitously cross-reacted with Env. More likely, however, interactions between proteins in solution (3D affinity), as measured by SPR or related techniques, differ from those at contacts between two cells or between a cell and a virus (2D affinity) (44). For example, whereas SPR was unable to detect any binding between CD4 and MHC class II (45), the affinity of CD4 for MHC class II on B cells could be measured in 2D using CD4-functionalized supported lipid bilayers (46). Therefore, under physiological conditions, germ line precursors of anti-CD4 binding site bNAbs, expressed on the surface of $B$ cells, might be engaged by membrane-anchored Env on the virion surface or on the surface of infected cells with sufficient affinity to trigger B cell maturation. In support of this idea, the germ line precursors of several anti-influenza HA bNAbs were found to bind to HA only when presented on membranes in the form of cell surface IgMs; as soluble IgGs, these precursors had no detectable affinity for HA (47). In the following sections, we have selected representative examples of affinity maturation 
in order to illustrate the multiple structural strategies that the antibodies employ to increase potency and breadth of pathogen neutralization.

\section{Preorganization, Rigidification, and Reorientation}

Antibody CH58 was isolated from a participant in the RV144 HIV vaccine efficacy trial. Like most bNAbs elicited in response to HIV-1 infection, $\mathrm{CH} 58$ is highly mutated (7). The structure of affinity-matured $\mathrm{CH} 58$ in complex with an Env V2 peptide showed that this bNAb targets V2 residue Lys169, which is a site of vaccine-induced immune pressure. Structures have also been determined for the putative germ line precursor of $\mathrm{CH} 58$ in unliganded form and bound to the V2 peptide (8). A comparison of these structures revealed that affinity maturation of $\mathrm{CH} 58$ is driven by the formation of two new salt bridges linking $\mathrm{V}_{\mathrm{L}} \mathrm{CDR} 1 \mathrm{Asn} 31 \rightarrow$ Asp and $\mathrm{V}_{\mathrm{H}}$ CDR1Ser28 $\rightarrow$ Arg to Lys171 and Asp180 of V2, respectively (Figure 1) (8). In addition, $\mathrm{V}_{\mathrm{L}} \mathrm{CDR} 3$ in the unbound germ line precursor adopts a different conformation in the CH58-V2 complex, implying flexibility. By contrast, the conformation of $\mathrm{V}_{\mathrm{L}} \mathrm{CDR} 3$ in the $\mathrm{CH} 58-\mathrm{V} 2$ complex is nearly identical to that in unbound matured $\mathrm{CH} 58$. Such preorganization of the $\mathrm{CH} 58$ paratope into a configuration more suitable for binding $\mathrm{V} 2$, accompanied by rigidification of $\mathrm{V}_{\mathrm{L}} \mathrm{CDR} 3$ to lower the entropic cost of complex formation, further contributes to the 2,000-fold affinity increase during maturation. Paratope preorganization and rigidification have also been described for the CH65 lineage of anti-influenza virus HA antibodies (21), underscoring the general utility of these mechanisms for improving affinity (26-29).

A related study used hydrogen/deuterium exchange in combination with mass spectrometry (HDX/MS) to investigate how affinity maturation alters the dynamics of bNAbs against HIV-1 Env (12). Importantly, the high variability and constantly evolving nature of HIV-1 Env distinguish this conformationally dynamic glycoprotein from the static model antigens used in studies of affinity maturation prior to NGS $(23-26,30)$. HDX/MS directly measures local protein dynamics by monitoring backbone amide deuterium uptake when the protein is diluted into a solution of $\mathrm{D}_{2} \mathrm{O}$. Dynamic regions of a protein take up deuterium more rapidly than stable regions. HDX/MS was used to compare the local dynamics of the predicted germ line and affinity-matured forms of two bNAbs (VRC03 and VRC-PG04) specific for the CD4 binding site of HIV-1 Env (12). In both cases, the paratopes of the matured bNAbs were less dynamic overall that those of their germ line counterparts, in agreement with previous evidence that paratopes become more rigid during the maturation process $(28$, $30,48)$. Surprisingly, however, the largest decreases in dynamics occurred at the periphery of the paratopes, at sites adjacent to Env glycans, rather than at primary Env-contacting sites. A similar pattern was observed for a bNAb (CAP256-VRC26) specific for
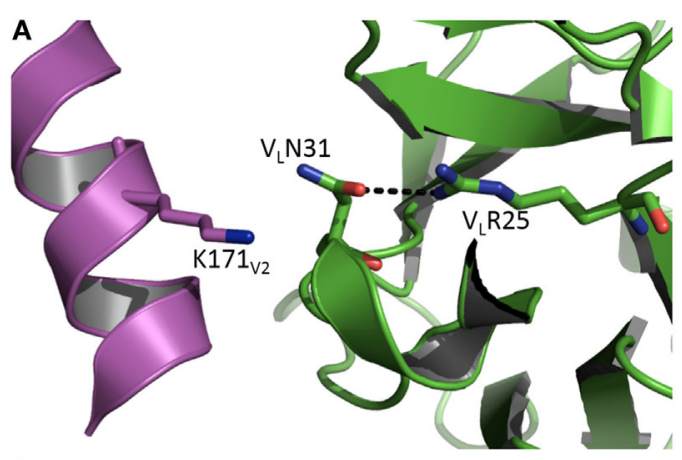

C

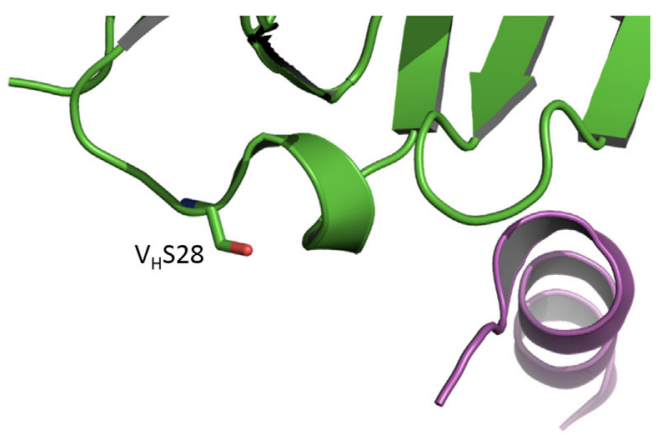

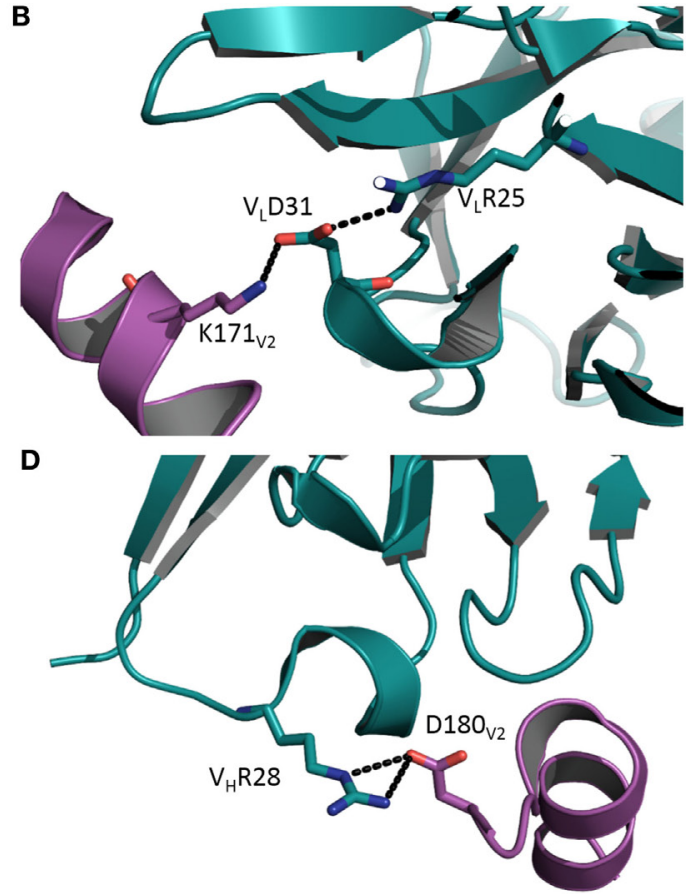

FIGURE 1 Affinity maturation through formation of additional interactions with antigen. (A) Close-up view of the interface between the germ line precursor of antibody $\mathrm{CH} 58$ and the $\mathrm{V} 2$ peptide of HIV-1 envelope glycoprotein in the vicinity of V2 Lys171 (Protein Data Bank accession code $4 \mathrm{RIS}$ ) (8). $\mathrm{V}_{\mathrm{L}}$ is green; $\mathrm{V} 2$ is magenta. (B) In affinity-matured $\mathrm{CH} 58$, the somatic mutation $V_{L}$ Asn31 $\rightarrow$ Asp allows formation of a stabilizing salt bridge (dotted black line) to $V_{2}$ Lys 171 . $V_{L}$ is teal. (C) Close-up of the interface between the germ line precursor of $\mathrm{CH} 58$ and the $\mathrm{V} 2$ peptide in the vicinity of $\mathrm{V}_{\mathrm{H}} \mathrm{Ser} 28$ (4HPO) (7). $\mathrm{V}_{\mathrm{H}}$ is green; $\mathrm{V} 2$ is magenta. (D) In affinity-matured $\mathrm{CH} 58$, the mutation $\mathrm{V}_{\mathrm{H}}$ Ser28 $\rightarrow$ Arg results in formation of a bidentate salt bridge with $\mathrm{V}_{2}$ Asp180. $\mathrm{V}_{\mathrm{H}}$ is teal. This residue was not visible in (C) due to disorder in the C-terminus of the V2 peptide. 
the V1/V2 quaternary epitope of HIV-1 Env. This stabilization of the paratope periphery may serve to minimize potential clashes with nearby Env glycans, while maintaining critical binding interactions mediated by the center of the paratope. It is probably not coincidental that a similar focus of affinity maturation on sites peripheral rather than central to the interface with antigen was also observed for anti-HEL antibodies (30).

Antibodies of the $\mathrm{CH} 103$ lineage block the CD4 binding site of HIV-1 via interactions dominated by $\mathrm{V}_{\mathrm{H}} \mathrm{CDR} 3$ (13). Affinity maturation of $\mathrm{CH} 103$ is associated with mutations in both contacting and non-contacting residues, including framework (FR) residues distant from the interface with Env. Structural analysis of the putative germ line precursor of $\mathrm{CH} 103$ and of two intermediates in the maturation pathway revealed a shift in the relative orientation of the $\mathrm{V}_{\mathrm{L}}$ and $\mathrm{V}_{\mathrm{H}}$ domains during evolution of the $\mathrm{CH} 103$ lineage, corresponding to a root mean squared deviation in $\alpha$-carbon positions of $2.1 \AA$ (Figure 2A) (14). This shift is mediated by several mutations at the $V_{L} / V_{H}$ interface, including a leucine-to-valine substitution at FR position $\mathrm{V}_{\mathrm{L}} 46$ that not only contributes to reorienting the $\mathrm{V}_{\mathrm{L}}$ domain but also to reconfiguring $\mathrm{V}_{\mathrm{H}} \mathrm{CDR} 3$ (Figure 2B). Although not as important as the $\mathrm{V}_{\mathrm{L}}$ Leu46 $\rightarrow$ Val mutation, the neighboring $\mathrm{V}_{\mathrm{L}}$ Tyr $49 \rightarrow$ Phe and $\mathrm{V}_{\mathrm{H}} \mathrm{Phe} 100 \rightarrow$ Tyr mutations, which are also located in the $\mathrm{V}_{\mathrm{L}}$ / $V_{H}$ interface, may further contribute to $V_{L} / V_{H}$ reorientation. Most likely, $\mathrm{V}_{\mathrm{L}} / \mathrm{V}_{\mathrm{H}}$ reorientation occurred in response to insertions in the V5 loop of Env during infection, which had allowed the virus to escape neutralization by progenitors of $\mathrm{CH} 103$. Displacement of $\mathrm{V}_{\mathrm{L}}$ away from $\mathrm{V} 5$ allowed accommodation of insertions in V5 without steric hindrance (14). In addition, the conformation of $\mathrm{V}_{\mathrm{H}} \mathrm{CDR} 3$ in the germ line precursor of $\mathrm{CH} 103$ is incompatible with gp120 binding, at least as observed in the CH103-gp120 complex (13), thereby necessitating rearrangement of this loop during the maturation process (14).

In sharp contrast to bNAbs against HIV-1, which are highly mutated, the potent human anti-Middle East respiratory syndrome coronavirus antibody $\mathrm{m} 336$ is almost germ line, with only one somatic mutation in the $\mathrm{H}$ chain (49). The structure of m336 in complex with the MERS-CoV receptor-binding domain showed that the IGV1-69-derived $\mathrm{H}$ chain contributes $>85 \%$ of the binding surface. The subnanomolar affinity of m336 despite the near absence of somatic mutations results from direct interactions with germ line-encoded $\mathrm{V}_{\mathrm{H}} \mathrm{CDR} 2$ and $\mathrm{V}_{\mathrm{H}}$ framework region $3\left(\mathrm{~V}_{\mathrm{H}} \mathrm{FR} 3\right)$ residues and with recombination-generated residues in the $\mathrm{V}_{\mathrm{H}} \mathrm{DJ} \mathrm{J}_{\mathrm{H}}$ junction (49). Like m336, the anti-influenza HA bNAb CR6261 uses the IGV1-69 $\mathrm{V}_{\mathrm{H}}$ gene segment (47). Virus neutralization depended solely on the $\mathrm{H}$ chain, and only seven somatic mutations in $\mathrm{V}_{\mathrm{H}} \mathrm{CDR} 1$ and $\mathrm{V}_{\mathrm{H}} \mathrm{FR} 3$ were required for maximum affinity.

To systematically dissect the contribution of mutations in FR residues to affinity maturation, deep mutational scanning was applied to the anti-vascular endothelial cell growth factor antibody G6.31 (50). A number of FR mutations at positions distal to the CDRs were found to improve the affinity and/or thermostability of G6.31. In particular, the FR mutation $\mathrm{V}_{\mathrm{L}} \mathrm{Phe} 83 \rightarrow \mathrm{Ala}$, which is $\sim 25 \AA$ away from the antigen-binding site, increased both affinity and stability by altering the orientation of the constant domains $\left(\mathrm{C}_{\mathrm{L}}\right.$ and $\left.\mathrm{C}_{\mathrm{H}} 1\right)$ relative to $\mathrm{V}_{\mathrm{L}}$ and $\mathrm{V}_{\mathrm{H}}$, as well as the orientation of $\mathrm{V}_{\mathrm{L}}$ to $\mathrm{V}_{\mathrm{H}}(50)$. As measured by HDX/MS, the $\mathrm{V}_{\mathrm{L}} \mathrm{Phe} 83 \rightarrow$ Ala mutation modulated the interdomain conformational dynamics of antibody G6.31. Furthermore, analysis of $>5,000$ human $V_{L}$ sequences showed that somatic mutations occur frequently at position 83, strongly suggesting its biological relevance in repertoire selection.
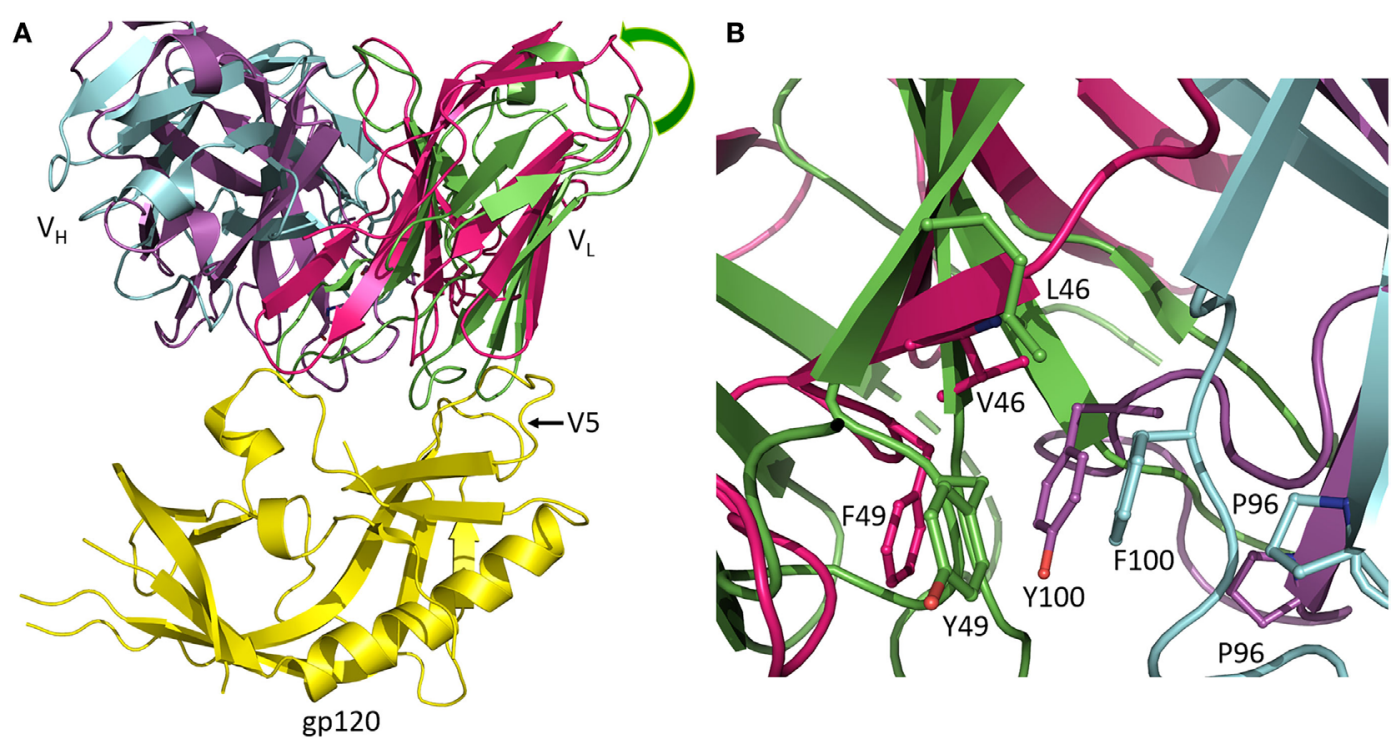

FIGURE 2 | Reorientation of $V_{L}$ and $V_{H}$ domains in response to viral escape mutations. (A) Superposition of the germ line precursor of $C H 103\left(V_{L}\right.$ and $V_{H}$ domains are green and cyan, respectively) (4QHL) (14) onto matured $\mathrm{CH} 103\left(\mathrm{~V}_{\mathrm{L}}\right.$ and $\mathrm{V}_{\mathrm{H}}$ domains are red and magenta, respectively) in complex with envelope glycoprotein gp120 (yellow) (4JAN) (13). During affinity maturation, a shift occurred in the orientation of $V_{L}$ with respect to $V_{H}$. The shift is an adaptation to insertions in the gp120 $\checkmark 5$ loop during infection. Movement of $V_{L}$ away from gp120 enables accommodation of the $V_{5}$ insertion. (B) Close-up view of the $V_{L} N_{H}$ interface in the vicinity of the $V_{L}$ Leu $46 \rightarrow$ Val mutation showing changes in interdomain contacts and rearrangement of $\mathrm{V}_{\mathrm{H}} \mathrm{CDR} 3$. 


\section{Affinity Maturation of Glycan-Binding Antibodies}

Besides high sequence variability, another feature of HIV-1 Env that distinguishes it from model antigens such as HEL used in previous studies of affinity maturation is glycosylation. Indeed, extensive $\mathrm{N}$-glycosylation masks much of the Env protein surface from antibody recognition. Nevertheless, a number of potent bNAbs have been discovered that penetrate this glycan shield and engage both carbohydrate and protein antigenic determinants $(51,52)$. In the most thoroughly studied example to date, the PGT121 family of bNAbs was shown to bind to N-glycans located in a high-mannose patch centered on the highly conserved Asn332 glycan and to protein elements at the base of the V3 loop $(15,16)$.

As revealed by NGS and X-ray crystallography, the putative germ line precursor of the PGT121 family splits into two evolutionary branches that differ considerably in how they interact with Env glycans (Figures 3A,B). One branch, exemplified by PGT124, contacts only the Asn332 glycan (16), whereas the other branch, exemplified by PGT122, also contacts the Asn137, Asn156, and Asn301 glycans (15). PGT124 and PGT122 employ a common set of CDR residues to contact the Asn332 glycan and V3 loop, nearly all of which are also found in the germ line precursor. This conservation suggests that a critical event in triggering the antibody response is simultaneous recognition of both carbohydrate and protein determinants.

Antibodies PGT124 and PGT122 share similar binding site architectures with long $\mathrm{V}_{\mathrm{H}} \mathrm{CDR} 3$ loops that pack against the entire length of the Asn 332 glycan, thereby penetrating the glycan shield to reach the Env protein surface below (Figure 3C) (16). In both antibodies, as well as in the germ line precursor, a closed face on one side of the paratope engages the Asn332 glycan. A second, open face differs between PGT124 and PGT122. For PGT124, the open face enables avoidance of neighboring glycans through a shift of $\mathrm{V}_{\mathrm{H}} \mathrm{CDR} 3$ away from its equivalent position in PGT122 (Figure 3C). For PGT122, by contrast, mutations during affinity maturation result in productive interactions between $\mathrm{V}_{\mathrm{H}} \mathrm{CDR} 2$ and the Asn137 glycan. In agreement with the structural data, deletion of the Asn332 glycan abolished PGT124 neutralization of nearly all HIV-1 isolates, whereas deletion of neighboring glycans had little or no effect (16). Conversely, PGT122 is less reliant on the Asn332 glycan than PGT124 for virus neutralization because of its ability to utilize alternative glycans at Asn137 and Asn301 to achieve high-affinity binding.
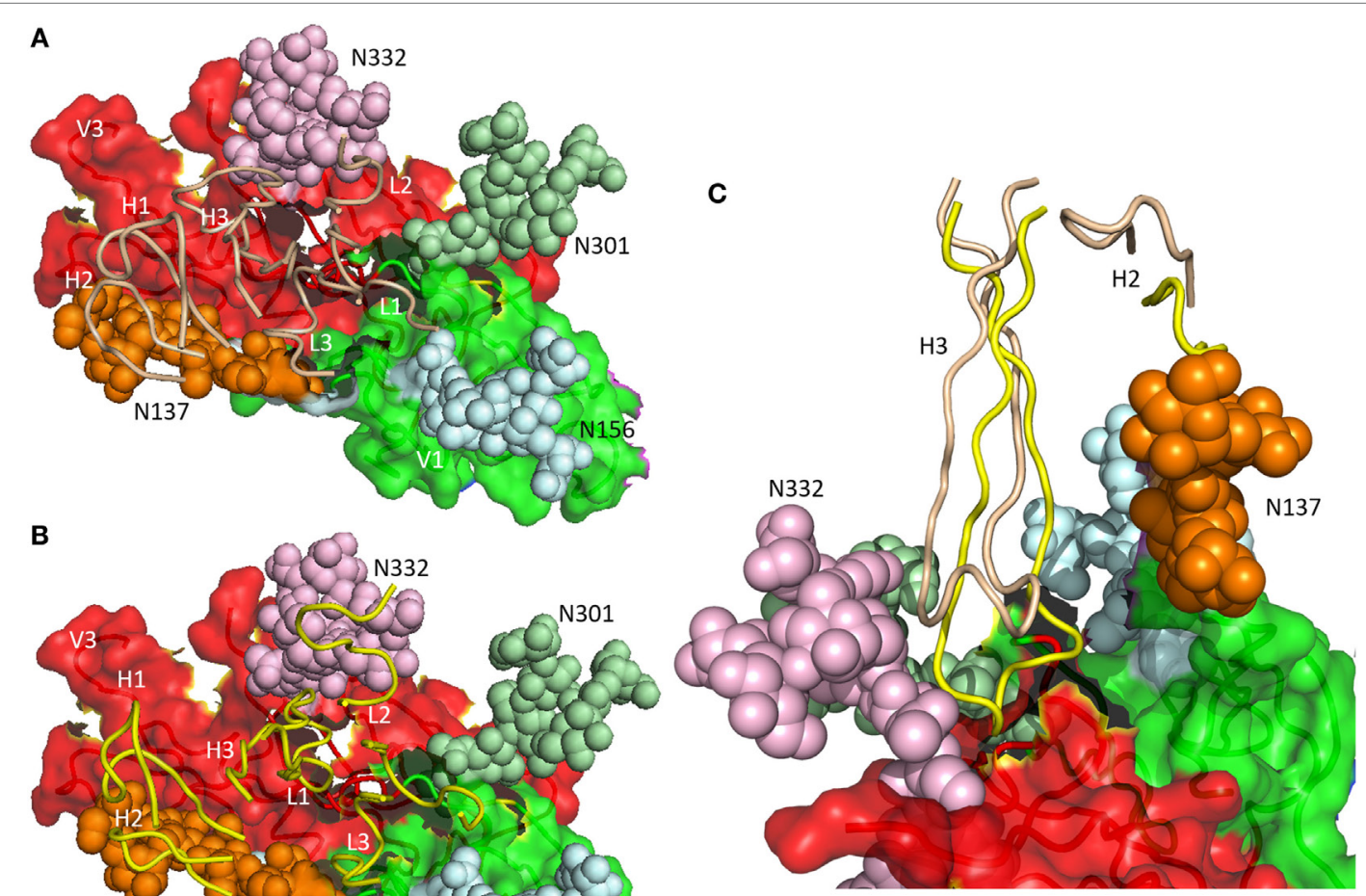

FIGURE 3 | Differential glycan recognition by affinity-matured antibodies. (A) Positions of complementarity-determining region (CDR) loops (wheat) of matured antibody PGT124 on envelope glycoprotein (Env) gp120 (4R2G) (16). V L CDR loops are labeled L1-L3; VH CDR loops are labeled H1-H3. The V1 (green) and V3 (red) regions of gp120 are depicted as molecular surfaces. Glycans are drawn as spheres and labeled N137, N156, N301, and N332. The PGT124 epitope is composed of V1, V3, and the N332 glycan. (B) Positions of CDR loops (yellow) of matured antibody PGT122 on Env gp120 (4NCO) (15). The PGT122 epitope is composed of V1 and V3, as well as all four glycans at N137, N156, N301, and N332. (C) VHCDR3 of PGT122 (yellow) contacts both the N137 and N332 glycans. $\mathrm{V}_{\mathrm{H}} \mathrm{CDR} 3$ of PGT124 (wheat) contacts only the N332 glycan due to a shift in position relative to $\mathrm{V}_{\mathrm{H}} \mathrm{CDR} 3$ of PGT122. 
Recently, NGS of HIV-1 longitudinal cohorts has been performed to investigate coevolution of HIV-1 Env and antibodies targeting this glycoprotein and to identify viral variants that initiate maturation of bNAbs $(18,53,54)$. These studies have shown that viral escape generates a pool of diverse epitope variants and that somatic hypermutation, acting in parallel, creates antibodies with differential ability to neutralize these variants. Thus, antibodies from the CAP256 and PCT64 lineages, which were isolated independently from two different HIV-1 infected African patients, both target the V2 apex epitope of the Env trimer (18, $53,54)$. The crystal structure of bNAb PCT64-35B, isolated at 35 months postinfection, showed that the somatically mutated 25 -residue $\mathrm{V}_{\mathrm{H}} \mathrm{CDR} 3$ loop adopts a $\beta$-hairpin conformation that projects above the other CDRs (18). The extended conformation and anionic character of this $\mathrm{V}_{\mathrm{H}} \mathrm{CDR}$, which contains at least one sulfotyrosine, probably enable this loop to penetrate between the glycans that shield the V2 apex epitope to contact the positively charged V1/V2 protein surface of the Env trimer. Moreover, in the PCT64 donor, Env glycoform heterogeneity may have played a role in activating B cell precursors of the PCT64 lineage by allowing germ line antibody binding to early Env trimer forms lacking complex or hybrid glycans at key positions (18).

According to the polyreactivity hypothesis, B cells initially produce germ line antibodies with conformationally flexible combining sites that are able to recognize diverse antigens with low affinity $(12,28,48)$. In this way, the immune system can respond to an enormous variety of potential antigens, whose numbers dwarf theoretical estimates of the clonal diversity of germ line antibodies. As described earlier, studies of immune responses to haptens, model proteins, and HIV-1 Env have shown that affinity maturation generates antibodies with higher affinity and specificity than germ line antibodies, at least in part through rigidification of the paratope. However, a recent study of glycan-specific antibodies has suggested an alternative pathway for antibody evolution that is distinct from the polyreactive germ line pathway (55).

A combination of glycan microarrays and molecular dynamics (MD) simulations was used to investigate the affinity maturation of two antibodies (3F8 and ch14.18) specific for the ganglioside GD2, a tumor-associated carbohydrate antigen overexpressed in various cancers, notably neuroblastoma and melanoma (55). Surprisingly, the putative germ line antibodies, although of lower affinity than their matured counterparts, were just as highly selective for CD2 as the matured antibodies when screened against hundreds of glycans and thousands of proteins. Possible reasons for this lack of observable polyreactivity were investigated by MD simulations of germ line and affinity-matured 3F8 and ch14.18 (55). These simulations revealed that, rather than becoming more rigid, the binding sites of the matured anti-G2 antibodies showed an increase in flexibility relative to the binding sites of the germ line antibodies. Most likely, affinity maturation of 3F8 and ch14.18 was enthalpically driven by an increase in direct or water-mediated hydrogen bonds to G2, rather than entropically driven by a decrease in binding site flexibility. The high selectivity of germ line antibodies to the ganglioside G2, compared to the polyreactivity of antibodies to other antigens $(12,28,48)$, may reduce the risk of developing autoimmune diseases such as
Guillain-Barré syndrome, which is associated with antibodies to the structurally related ganglioside GM2 (56).

\section{Indels in Antibody Affinity Maturation}

Multibase in-frame indels are introduced during somatic hypermutation in germinal center B cells along with point mutations (57). As revealed by NGS, the frequency of indels among total somatic mutations in normal human B cell repertoires is low ( $2 \%$ ) (58). In sharp contrast, $\sim 40 \%$ of bNAbs against HIV-1 Env contain indels, ranging in size from 1 to 11 amino acids (59). Indels are the primary means by which antibodies can effect large changes in steric volume comparable to those associated with addition or removal of glycans. Indeed, the role of indels in bNAb maturation is to accommodate glycans, penetrate the glycan shield, and/or increase the number of interfacial contacts.

A distinguishing feature of VRC01-class bNAbs that target the CD4 binding site of Env is a deletion of two to six amino acids in $\mathrm{V}_{\mathrm{L}} \mathrm{CDR} 1(9,10)$. The function of this deletion is to avoid a steric clash with the Asn276 glycan of loop D of gp120, such that reversion of the deletion to germ line markedly diminished binding. Notably, the $\mathrm{V}_{\mathrm{L}} \mathrm{CDR} 1$ deletion appears across multiple lineages of VRC01-class bNAbs from different individuals, suggesting that there are few other viable solutions to fitting an antibody into the CD4 binding site of Env.

The structure of antibody 8ANC195 in complex with trimeric Env showed that this bNAb recognizes an epitope that spans the gp41 and gp120 Env subunits (20). An insertion of five amino acids in $\mathrm{V}_{\mathrm{H}} \mathrm{FR} 3$ extends between the Asn234 and Asn276 glycans of gp120, establishing productive interactions with both glycans and enabling 8ANC195 to penetrate the glycan shield to contact the protein surface of Env (Figure 4). Like 8ANC195, bNAb $35 \mathrm{O} 22$ binds trimeric Env at the gp41-gp120 interface (60). An

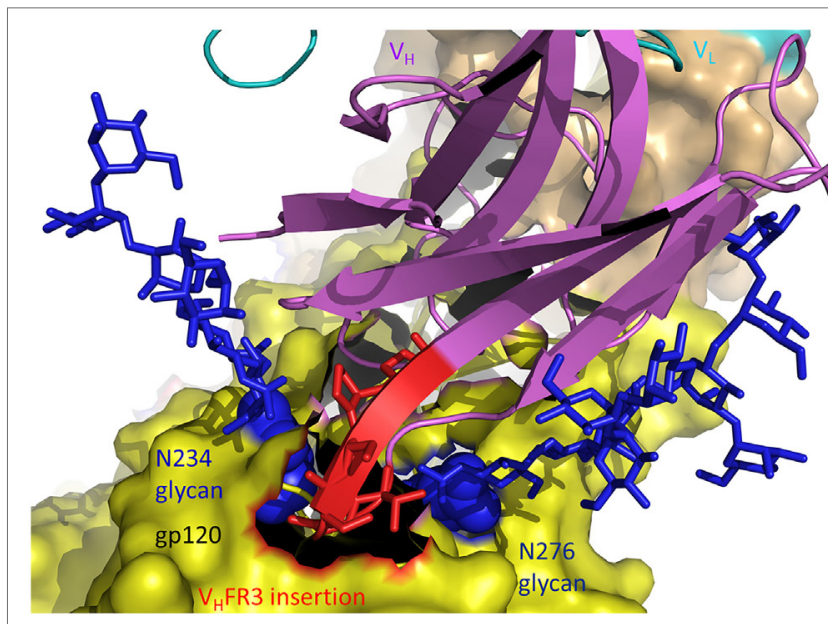

FIGURE 4 | Role of insertions in antibody affinity maturation. An insertion of five amino acids in $V_{H}$ framework region $3\left(V_{H} F R 3\right)$ of matured antibody 8ANC195 enables $V_{H} F R 3$ to extend between the N234 and N276 glycans of envelope glycoprotein (Env) gp120 and contact protein beneath the glycan shield (5CJX) (20). $V_{H}$ and $V_{L}$ are magenta and cyan, respectively. The insertion in $V_{H} F R 3$ is red. Env gp120 (yellow) is drawn as a molecular surface. Glycans are represented as blue sticks. 
insertion of eight amino acids in $\mathrm{V}_{\mathrm{H}} \mathrm{FR} 3$ projects into the cleft between the Env subunits, resulting in additional stabilizing contacts with antigen that increase the neutralization potency of the matured antibody compared to its germ line precursor.

\section{CONCLUSION}

Structural studies of antibody affinity maturation spanning nearly 30 years have identified a diversity of biophysical mechanisms underlying this prototypical example of molecular evolution. These include improved shape complementarity at the interface with antigen, increased buried surface area upon complex formation, additional interfacial polar or hydrophobic interactions, preorganization or rigidification of the antigen-binding site, and $\mathrm{V}_{\mathrm{L}} / \mathrm{V}_{\mathrm{H}}$ reorientation. Over the last 5 years, NGS has allowed the reconstruction of antibody clonal lineages in immune responses to viral pathogens, mainly HIV-1, which was not possible previously. These remarkable studies have revealed how antibodies evolve to penetrate the glycan shield of HIV-1 Env and how the virus in turn evolves to escape neutralization. New insights into the coevolution of viruses and antiviral antibodies will come from NGS of both Env variants and antibodies targeting these variants in well-documented longitudinal cohorts of African HIV-1 patients, as demonstrated recently $(18,53,54)$. Although HIV-1 has so far been the primary focus of studies using NGS and single-cell analysis to identify germ line progenitors and intermediates along antibody maturation pathways, the future application of these methods to other pathogens, such as dengue virus and Ebola virus, will undoubtedly uncover new structural strategies for generating high-affinity binders to bolster host immune defense.

\section{REFERENCES}

1. Rajewsky K. Clonal selection and learning in the antibody system. Nature (1996) 381:751-8. doi:10.1038/381751a0

2. Neuberger MS. Antibodies: a paradigm for the evolution of molecular recognition. Biochem Soc Trans (2002) 30:341-50. doi:10.1042/bst030a047

3. Sundberg EJ, Mariuzza RA. Molecular recognition in antigen-antibody complexes. Adv Protein Chem (2002) 61:119-60. doi:10.1016/S0065-3233(02) 61004-6

4. Tonegawa S. Somatic generation of antibody diversity. Nature (1983) 302:575-81. doi:10.1038/302575a0

5. Wardemann H, Busse CE. Novel approaches to analyze immunoglobulin repertoires. Trends Immunol (2017) 38:471-82. doi:10.1016/j.it.2017. 05.003

6. Kepler TB, Wiehe K. Genetic and structural analyses of affinity maturation in the humoral response to HIV-1. Immunol Rev (2017) 275:129-44. doi:10.1111/ imr. 12513

7. Liao HX, Bonsignori M, Alam SM, McLellan JS, Tomaras GD, Moody MA, et al. Vaccine induction of antibodies against a structurally heterogeneous site of immune pressure within HIV-1 envelope protein variable regions 1 and 2. Immunity (2013) 38:176-86. doi:10.1016/j.immuni.2012.11.011

8. Nicely NI, Wiehe K, Kepler TB, Jaeger FH, Dennison SM, Rerks-Ngarm S, et al. Structural analysis of the unmutated ancestor of the HIV-1 envelope V2 region antibody $\mathrm{CH} 58$ isolated from an RV144 vaccine efficacy trial vaccinee. EBioMedicine (2015) 2:713-22. doi:10.1016/j.ebiom.2015.06.016

9. Zhou T, Zhu J, Wu X, Moquin S, Zhang B, Acharya P, et al. Multidonor analysis reveals structural elements, genetic determinants, and maturation pathway for
It is becoming increasingly evident that the contribution of somatic hypermutation to bNAb development must be considered in designing vaccine immunogens for different viral pathogens. At one extreme, bNAbs against some viruses, such as MERS-CoV (49) and hepatitis C virus (61), appear to exist naturally with relatively few somatic mutations. Importantly, somatic mutations were found not to be required for binding of germ line ancestors of these bNAbs to their viral targets, which may facilitate elicitation of effective vaccine responses. At the other extreme, bNAbs against viruses such as HIV-1 are highly somatically mutated and generally require years to develop in infected individuals. Furthermore, germ line precursors of these bNAbs often exhibit little or no detectable affinity for HIV-1 Env, making elicitation of such antibodies by vaccination a formidable challenge (62). Current strategies to overcome this roadblock involve initial activation of naïve mature B cells expressing germ line B cell receptors with engineered germ line-binding immunogens, followed by sequential vaccinations with immunogens designed to bind intermediate antibodies in order to guide the immune system through complex maturation pathways that ultimately lead to antibodies with specific somatic mutations conferring high affinity and neutralization potency (63-66).

\section{AUTHOR CONTRIBUTIONS}

$\mathrm{AM}$ and RM conceived and wrote the manuscript.

\section{FUNDING}

This study was supported by National Institutes of Health grant AI132213 to RM.
HIV-1 neutralization by VRC01-class antibodies. Immunity (2013) 39:245-58 doi:10.1016/j.immuni.2013.04.012

10. Scharf L, West AP, Sievers SA, Chen C, Jiang S, Gao H, et al. Structural basis for germline antibody recognition of HIV-1 immunogens. Elife (2016) 5:1-24. doi:10.7554/eLife.13783

11. Jardine J, Julien JP, Menis S, Ota T, Kalyuzhniy O, McGuire A, et al. Rational HIV immunogen design to target specific germline B cell receptors. Science (2013) 340:711-6. doi:10.1126/science.1234150

12. Davenport TM, Gorman J, Joyce MG, Zhou T, Soto C, Guttman M, et al. Somatic hypermutation-induced changes in the structure and dynamics of HIV-1 broadly neutralizing antibodies. Structure (2016) 24:1346-57. doi:10.1016/j.str.2016.06.012

13. Liao HX, Lynch R, Zhou T, Gao F, Alam SM, Boyd SD, et al. Co-evolution of a broadly neutralizing HIV-1 antibody and founder virus. Nature (2013) 496:469-76. doi:10.1038/nature12053

14. Fera D, Schmidt AG, Haynes BF, Gao F, Liao HX, Kepler TB, et al. Affinity maturation in a broadly neutralizing B-cell lineage through reorientation of variable domains. Proc Natl Acad Sci U S A (2014) 111:10275-80. doi:10.1073/ pnas.1409954111

15. Julien JP, Cupo A, Sok D, Stanfield RL, Lyumkis D, Deller MC, et al. Crystal structure of a soluble cleaved HIV-1 envelope trimer. Science (2013) 342:1477-83. doi:10.1126/science.1245625

16. Garces F, Sok D, Kong L, McBride R, Kim HJ, Saye-Francisco KF, et al. Structural evolution of glycan recognition by a family of potent HIV antibodies. Cell (2014) 159:69-79. doi:10.1016/j.cell.2014.09.009

17. Garces F, Lee JH, de Val N, de la Pena AT, Kong L, Puchades C, et al. Affinity maturation of a potent family of HIV antibodies is primarily focused 
on accommodating or avoiding glycans. Immunity (2015) 43:1053-63. doi:10.1016/j.immuni.2015.11.007

18. Landais E, Murrell B, Briney B, Murrell S, Rantalainen K, Berndsen ZT, et al. HIV envelope glycoform heterogeneity and localized diversity govern the initiation and maturation of a V2 apex broadly neutralizing antibody lineage. Immunity (2017) 47:990-1003. doi:10.1016/j.immuni.2017.11.002

19. Doria-Rose NA, Schramm CA, Gorman J, Moore PL, Bhiman JN, DeKosky BJ, et al. Developmental pathway for potent V1V2-directed HIVneutralizing antibodies. Nature (2014) 509:55-62. doi:10.1038/nature13036

20. Scharf L, Wang H, Gao H, Chen S, McDowall AW, Bjorkman PJ. Broadly neutralizing antibody 8ANC195 recognizes closed and open states of HIV-1 Env. Cell (2015) 162:1379-90. doi:10.1016/j.cell.2015.08.035

21. Schmidt AG, Xu H, Khan AR, O'Donnell T, Khurana S, King LR, et al. Preconfiguration of the antigen-binding site during affinity maturation of a broadly neutralizing influenza virus antibody. Proc Natl Acad Sci U S A (2013) 110:264-9. doi:10.1073/pnas.1218256109

22. Joyce MG, Wheatley AK, Thomas PV, Chuang GY, Soto C, Bailer RT, et al. Vaccine-induced antibodies that neutralize group 1 and group 2 influenza A viruses. Cell (2016) 166:609-23. doi:10.1016/j.cell.2016.06.043

23. Alzari PM, Spinelli S, Mariuzza RA, Boulot G, Poljak RJ, Jarvis JM, et al. Threedimensional structure determination of an anti-2-phenyloxazolone antibody: the role of somatic mutation and heavy/light chain pairing in the maturation of an immune response. EMBO J (1990) 9:3807-14.

24. Mizutani R, Miura K, Nakayama T, Shimada I, Arata Y, Satow Y. Threedimensional structures of the Fab fragment of murine N1G9 antibody from the primary immune response and of its complex with (4-hydroxy-3nitrophenyl)acetate.J Mol Biol (1995) 254:208-22. doi:10.1006/jmbi.1995.0612

25. Yuhasz SC, Parry C, Strand M, Amzel LM. Structural analysis of affinity maturation: the three-dimensional structures of complexes of an anti-nitrophenol antibody.MolImmunol(1995)32:1143-55.doi:10.1016/0161-5890(95)00063-1

26. Wedemayer GJ, Patten PA, Wang LH, Schultz PG, Stevens RC. Structural insights into the evolution of an antibody combining site. Science (1997) 276:1665-9. doi:10.1126/science.276.5319.1665

27. Furukawa K, Akasako-Furukawa A, Shirai H, Nakamura H, Azuma T. Junctional amino acids determine the maturation pathway of an antibody. Immunity (1999) 11:329-38. doi:10.1016/S1074-7613(00)80108-9

28. Manivel V, Sahoo NC, Salunke DM, Rao KV. Maturation of an antibody response is governed by modulations in flexibility of the antigen-combining site. Immunity (2000) 13:611-20. doi:10.1016/S1074-7613(00)00061-3

29. Wang F, Sen S, Zhang Y, Ahmad I, Zhu X, Wilson IA, et al. Somatic hypermutation maintains antibody thermodynamic stability during affinity maturation. Proc Natl Acad Sci U S A (2013) 110:4261-6. doi:10.1073/pnas. 1301810110

30. Li Y, Li H, Yang F, Smith-Gill SJ, Mariuzza RA. X-ray snapshots of the maturation of an antibody response to a protein antigen. Nat Struct Biol (2003) 10:482-8. doi:10.1038/nsb930

31. Tomlinson IM, Walter G, Jones PT, Dear PH, Sonnhammer EL, Winter G. The imprint of somatic hypermutation on the repertoire of human germline V genes. J Mol Biol (1996) 256:813-7. doi:10.1006/jmbi.1996.0127

32. DeKosky BJ, Lungu OI, Park D, Johnson EL, Charab W, Chrysostomou C, et al. Large-scale sequence and structural comparisons of human naive and antigen-experienced antibody repertoires. Proc Natl Acad Sci U S A (2016) 113:E2636-45. doi:10.1073/pnas.1525510113

33. Wardemann H, Yurasov S, Schaefer A, Young JW, Meffre E, Nussenzweig MC. Predominant autoantibody production by early human B cell precursors. Science (2003) 301:1374-7. doi:10.1126/science.1086907

34. Trück J, Ramasamy MN, Galson JD, Rance R, Parkhill J, Lunter G, et al. Identification of antigen-specific $B$ cell receptor sequences using public repertoire analysis. J Immunol (2015) 194:252-61. doi:10.4049/jimmunol.1401405

35. Parameswaran P, Liu Y, Roskin KM, Jackson KK, Dixit VP, Lee JY, et al. Convergent antibody signatures in human dengue. Cell Host Microbe (2013) 13:691-700. doi:10.1016/j.chom.2013.05.008

36. Tan YC, Blum LK, Kongpachith S, Ju CH, Cai X, Lindstrom TM, et al. High-throughput sequencing of natively paired antibody chains provides evidence for original antigenic sin shaping the antibody response to influenza vaccination. Clin Immunol (2014) 151:55-65. doi:10.1016/j.clim.2013.12.008

37. Kepler TB. Reconstructing a B-cell clonal lineage. I. Statistical inference of unobserved ancestors. F1000Res (2013) 2:103. doi:10.12688/f1000research.2-103.v1
38. Alam SM, Liao HX, Dennison SM, Jaeger F, Parks R, Anasti K, et al. Differential reactivity of germ line allelic variants of a broadly neutralizing HIV-1 antibody to a gp41 fusion intermediate conformation. J Virol (2011) 85:11725-31. doi:10.1128/JVI.05680-11

39. Bonsignori M, Hwang KK, Chen X, Tsao CY, Morris L, Gray E, et al. Analysis of a clonal lineage of HIV-1 envelope V2/V3 conformational epitope-specific broadly neutralizing antibodies and their inferred unmutated common ancestors. J Virol (2011) 85:9998-10009. doi:10.1128/JVI.05045-11

40. Dal Porto JM, Haberman AM, Kelsoe G, Shlomchik MJ. Very low affinity B cells form germinal centers, become memory B cells, and participate in secondary immune responses when higher affinity competition is reduced. J Exp Med (2002) 195:1215-21. doi:10.1084/jem.20011550

41. Shih TA, Meffre E, Roederer M, Nussenzweig MC. Role of BCR affinity in $\mathrm{T}$ cell dependent antibody responses in vivo. Nat Immunol (2002) 3:570-5. doi:10.1038/ni803

42. Hoot S, McGuire AT, Cohen KW, Strong RK, Hangartner L, Klein F, et al. Recombinant HIV envelope proteins fail to engage germline versions of anti-CD4bs bNAbs. PLoS Pathog (2013) 9:e1003106. doi:10.1371/journal. ppat.1003106

43. Xiao X, Chen W, Feng Y, Zhu Z, Prabakaran P, Wang Y, et al. Germline-like predecessors of broadly neutralizing antibodies lack measurable binding to HIV-1 envelope glycoproteins: implications for evasion of immune responses and design of vaccine immunogens. Biochem Biophys Res Commun (2009) 390:404-9. doi:10.1016/j.bbrc.2009.09.029

44. Huang J, Zarnitsyna VI, Liu B, Edwards LJ, Jiang N, Evavold BD, et al. The kinetics of two-dimensional TCR and pMHC interactions determine T-cell responsiveness. Nature (2010) 464:932-6. doi:10.1038/nature08944

45. Wang XX, Li Y, Yin Y, Mo M, Wang Q, Gao W, et al. Affinity maturation of human CD 4 by yeast surface display and crystal structure of a CD4-HLA-DR1 complex. Proc Natl Acad Sci U S A (2011) 108:15960-5. doi:10.1073/ pnas. 1109438108

46. Jönsson P, Southcombe JH, Santos AM, Huo J, Fernandes RA, McColl J, et al. Remarkably low affinity of CD4/peptide-major histocompatibility complex class II protein interactions. Proc Natl Acad Sci U S A (2016) 113:5682-7. doi:10.1073/pnas.1513918113

47. Lingwood D, McTamney PM, Yassine HM, Whittle JR, Guo X, Boyington JC, et al. Structural and genetic basis for development of broadly neutralizing influenza antibodies. Nature (2012) 489:566-70. doi:10.1038/nature11371

48. James LC, Roversi P, Tawfik DS. Antibody multispecificity mediated by conformational diversity. Science (2003) 299:1362-7. doi:10.1126/science.1079731

49. Ying T, Prabakaran P, Du L, Shi W, Feng Y, Wang Y, et al. Junctional and allele-specific residues are critical for MERS-CoV neutralization by an exceptionally potent germline-like antibody. Nat Commun (2015) 6:8223. doi:10.1038/ncomms 9223

50. Koenig P, Lee CV, Walters BT, Janakiraman V, Stinson J, Patapoff TW, et al. Mutational landscape of antibody variable domains reveals a switch modulating the interdomain conformational dynamics and antigen binding. Proc Natl Acad Sci U S A (2017) 114:E486-95. doi:10.1073/pnas.1613231114

51. Ward AB, Wilson IA. The HIV-1 envelope glycoprotein structure: nailing down a moving target. Immunol Rev (2017) 275:21-32. doi:10.1111/imr.12507

52. MacLeod DT, Choi NM, Briney B, Garces F, Ver LS, Landais E, et al. Early antibody lineage diversification and independent limb maturation lead to broad HIV-1 neutralization targeting the Env high-mannose patch. Immunity (2016) 44:1215-26. doi:10.1016/j.immuni.2016.04.016

53. Bhiman JN, Anthony C, Doria-Rose NA, Karimanzira O, Schramm CA, Khoza T, et al. Viral variants that initiate and drive maturation of V1V2directed HIV-1 broadly neutralizing antibodies. Nat Med (2015) 21:1332-6. doi:10.1038/nm.3963

54. Andrabi R, Su CY, Liang CH, Shivatare SS, Briney B, Voss JE, et al. Glycans function as anchors for antibodies and help drive HIV broadly neutralizing antibody development. Immunity (2017) 47:524-37. doi:10.1016/j. immuni.2017.08.006

55. Sterner E, Peach ML, Nicklaus MC, Gildersleeve JC. Therapeutic antibodies to ganglioside GD2 evolved from highly selective germline antibodies. Cell Rep (2017) 20:1681-91. doi:10.1016/j.celrep.2017.07.050

56. Ang CW, Jacobs BC, Brandenburg AH, Laman JD, van der Meché FG, Osterhaus $\mathrm{AD}$, et al. Cross-reactive antibodies against GM2 and CMVinfected fibroblasts in Guillain-Barré syndrome. Neurology (2000) 54:1453-8. doi:10.1212/WNL.54.7.1453 
57. Fukita Y, Jacobs H, Rajewsky K. Somatic hypermutation in the heavy chain locus correlates with transcription. Immunity (1998) 9:105-14. doi:10.1016/ S1074-7613(00)80592-0

58. Briney BS, Willis JR, Crowe JE Jr. Location and length distribution of somatic hypermutation-associated DNA insertions and deletions reveals regions of antibody structural plasticity. Genes Immun (2012) 13:523-9. doi:10.1038/ gene. 2012.28

59. Kepler TB, Liao HX, Alam SM, Bhaskarabhatla R, Zhang R, Yandava C, et al. Immunoglobulin gene insertions and deletions in the affinity maturation of HIV-1 broadly reactive neutralizing antibodies. Cell Host Microbe (2014) 16:304-13. doi:10.1016/j.chom.2014.08.006

60. Huang J, Kang BH, Pancera M, Lee JH, Tong T, Feng Y, et al. Broad and potent HIV-1 neutralization by a human antibody that binds the gp41-gp120 interface. Nature (2014) 515:138-43. doi:10.1038/nature13601

61. Bailey JR, Flyak AI, Cohen VJ, Li H, Wasilewski LN, Snider AE, et al. Broadly neutralizing antibodies with few somatic mutations and hepatitis $\mathrm{C}$ virus clearance. JCI Insight (2017) 2:92872. doi:10.1172/jci.insight.92872

62. Haynes BF, Kelsoe G, Harrison SC, Kepler TB. B-cell-lineage immunogen design in vaccine development with HIV-1 as a case study. Nat Biotechnol (2012) 30:423-33. doi:10.1038/nbt.2197

63. Briney B, Sok D, Jardine JG, Kulp DW, Skog P, Menis S, et al. Tailored immunogens direct affinity maturation toward HIV neutralizing antibodies. Cell (2016) 166(6):1459-70.e11. doi:10.1016/j.cell.2016.08.005
64. Escolano A, Steichen JM, Dosenovic P, Kulp DW, Golijanin J, Sok D, et al. Sequential immunization elicits broadly neutralizing anti-HIV-1 antibodies in Ig knockin mice. Cell (2016) 166:1445-8. doi:10.1016/j.cell.2016. 07.030

65. Jardine JG, Kulp DW, Havenar-Daughton C, Sarkar A, Briney B, Sok D, et al. HIV-1 broadly neutralizing antibody precursor B cells revealed by germlinetargeting immunogen. Science (2016) 351:1458-63. doi:10.1126/science. aad9195

66. Steichen JM, Kulp DW, Tokatlian T, Escolano A, Dosenovic P, Stanfield RL, et al. HIV vaccine design to target germline precursors of glycan-dependent broadly neutralizing antibodies. Immunity (2016) 45:483-96. doi:10.1016/j. immuni.2016.08.016

Conflict of Interest Statement: The authors declare that the research was conducted in the absence of any commercial or financial relationships that could be construed as a potential conflict of interest.

Copyright (C) 2018 Mishra and Mariuzza. This is an open-access article distributed under the terms of the Creative Commons Attribution License (CC BY). The use, distribution or reproduction in other forums is permitted, provided the original author(s) and the copyright owner are credited and that the original publication in this journal is cited, in accordance with accepted academic practice. No use, distribution or reproduction is permitted which does not comply with these terms. 